\title{
Clossed-vessel assisted microwave extraction of polychlorinated biphenyls in marine mussels
}

\author{
N. Carro ${ }^{*}$, I. García ${ }^{1}$, M. Llompart ${ }^{2}$ \\ ${ }^{1}$ Centro de Control de Calidad del Medio Marino, Peirao de Vilaxoán s/n. 36611, \\ Vilagarcía de Arousa, Pontevedra, Spain \\ ${ }^{2}$ Departamento de Química Analítica, Nutrición y Bromatología, Facultad de Química, \\ Avda das Ciencias s/n. 15706, Santiago Compostela, Spain
}

\begin{abstract}
A reliable and simple procedure to extract polychlorinated biphenyls (PCBs) from marine mussels using microwave energy is proposed. Freeze-dried mussels were subjected to MASE (Microwave Assisted Solvent Extraction) in a closed-vessel microwave system with $n$-pentane-sodium hydroxide $(5 \%)$ or dichloromethane-pentane $(1: 1)$ at different temperatures $(70$ and $90^{\circ} \mathrm{C}$ ), the extraction time was 10 minutes. Sample extract cleanup procedure was performed by using alumina. Gas chromatography-mass spectrometry and gas chromatography-electron capture detector were employed for individual congener identification and determination. The influence of the following variables on microwave extraction of PCBs has been studied: extraction temperature, solvent volume, solvent nature, cleanup procedure time and volume of sodium hydroxide solution. Recoveries for PCBs were between 77 and $106 \%$ with relative standard deviation between 2 to $20 \%$. Validation of the extraction process was carried out by processing a certified reference material. Microwave Assisted Solvent Extraction was compared to Soxhlet extraction.
\end{abstract}

Keywords. Microwave Assisted Solvent Extraction (MASE) - polychlorinated biphenyls (PCBs) - sample preparation - gas chromatography-electron capture detector - marine mussels.

\section{Introduction}

Conventional techniques have been widely used for extracting semivolatile organic compounds from environmental samples. These methods are time-consuming and require the use of large volumes of solvent that are often carcinogenic and toxic [1-2].

Microwave Assisted Solvent Extraction (MASE) may be actually considered as a real alternative to the conventional solvent extraction methods. The development of microwave commercial systems specially designed for the organic analysis using solvents transparent to microwaves in closed pressurized extraction vessels has increased the use of this technique [3-13]. These systems operate at elevated temperatures and pressures therefore they use a fiber optic temperature probe inserted into a representative vessel to monitor temperature during microwave heating, the representative vessel has also a pressure control side arm that will turn off the microwave energy if the pressure exceeds a set amount. The process of microwave extraction has been patented by Environment Canada [14]. However, MASE does not allow to separate the analyte from the other interferents, therefore, it is desirable to eliminate these extractables compounds in the extraction step. Saponification and alkaline decomposition are methods for the preparation of biological samples. They are used to remove fats in biosamples and to destroy some organic compounds [8].
Polychlorinated biphenyls (PCBs) may be considered the most ubiquitous pollutants, they have been found in nearly all marine plant and animal specimens and generally the PCBs levels increase through the food chain. Their high and indiscriminate use in various industrial activities, along with their chemical and physical stability have been responsible for the PCBs environmental contamination problem [15-17]. The use of marine mussels as bioindicator organism of PCBs pollution for checking water quality has been reviewed and is now well established [18-20].

The present work describes the optimization of a rapid and reliable analytical procedure using the microwave energy for the individual determination of principal PCBs in marine mussels. Results obtained on reference materials are reported; this method was compared with Soxhlet extraction; the microwave extraction is advantageous from the point of view of sample handling, amounts of sample and extractant, total run time and automation.

\section{Experimental}

\section{Material and apparatus}

Isooctane, $n$-pentane, dichloromethane, alumina (0.063$0.2 \mathrm{~mm}$ ) and anhydrous sodium sulphate for pesticide residue analysis were supplied by Merck (Darmstadt, Germany). Alumina was activated at $800{ }^{\circ} \mathrm{C}$ for 4 hours and 


\section{Original articles}

deactivated by addition of $6 \%$ water. Sodium sulfate was held at $400{ }^{\circ} \mathrm{C}$ for 24 hours to remove any organic matter and stored in a desiccator before use. Sodium hydroxide supplied by Panreack (Barcelona, Spain) was prepared diluting with water $(5 \%)$.

Polychlorinated biphenyls standards of chromatographic purity were purchased from Dr. Ehrenstorfer (Augsburg, Germany). Standards stock solutions were prepared by weighing an appropriate amount of each standard and diluting to $5 \mathrm{~mL}$ with isooctane. Working solutions were made by appropriate dilution of the stock solution. All solutions were stored at $4{ }^{\circ} \mathrm{C}$. For quantitative gas chromatographic determinations, calibration was carried out at four concentration levels for each congener spanning the range of 0.5 $130 \mu \mathrm{g} / \mathrm{L}$ and using PCB $155(500 \mu \mathrm{g} / \mathrm{L})$ as internal standard.

Experiments were performed on marine mussels from Ribadeo (North-West, Spain). Mussels were collected and immediately freeze dried. A certified reference material IAEA 142 (mussel tissue contaminated with PCBs purchased from International Atomic Energy Agency (P.O. Box 100, A-1400 Vienna, Austria)) was used. The certified contents for the PCB congeners 31, 28, 52, 101, 118, 153, 105, 138,156 and 180 , are respectively $0.9,1.3,3,3.1,3,6.4$, $1.4,5.6,6.4$ and $0.75 \mu \mathrm{g} / \mathrm{Kg}$ based on dry weight (95\% confidence intervals of the median).

Microwave experiments were performed with a 950 watt MES-1000 (CEM, Matthews, NC, USA) equipped with Teflon-lined $100 \mathrm{~mL}$ extraction vessels. It was operated under closed-vessel conditions at temperature and pressure up to $200{ }^{\circ} \mathrm{C}$ and $200 \mathrm{psi}$. The concentrated extracts were analysed by gas chromatography using a Perkin-Elmer Autosystem gas chromatograph equipped with an electron capture detector. A TRB-5 (Teknokroma, Barcelona, Spain) $5 \%$ diphenyldimethylsiloxane capillary column $(60 \mathrm{~m} \times$ $0.20 \mathrm{~mm}$ i.d., $0.4 \mu \mathrm{m}$ phase thickness) was used. Carrier gas was hydrogen supplied by Air Liquid (Spain). The chromatographic conditions were as follows: injector temperature (splitless mode, $1.8 \mathrm{~min}$.) $270{ }^{\circ} \mathrm{C}$, electron capture detector temperature $365^{\circ} \mathrm{C}$ and column temperature program $90{ }^{\circ} \mathrm{C}(3 \mathrm{~min})$ to $215^{\circ} \mathrm{C}(40 \mathrm{~min})$ at $30^{\circ} \mathrm{C} / \mathrm{min}$ and $275^{\circ} \mathrm{C}\left(30 \mathrm{~min}\right.$.) at $5^{\circ} \mathrm{C} / \mathrm{min}$, carrier gas flow at $1 \mathrm{~mL} / \mathrm{min}$. The identification of extracted compounds was performed on a Varian (Walnut Creek, CA, WA) Saturn 2000 gas chromatograph-ion trap detector mass spectrometer provided with a Varian 1078 Split-Splitless injector. A 5-MS (Varian) $5 \%$ diphenyldimethylsiloxane capillary column $(30 \mathrm{~m} \times$ $0.25 \mathrm{~mm}$ i.d., $0.25 \mu \mathrm{m}$ phase thickness) was used. Carrier gas was helium supplied by Air Liquid (Spain). Chromatographic conditions were identical to those described above. Mass spectrometry conditions are summarized in the table I.

\section{Sample preparation}

The used extractant solvents were pentane or pentanedichloromethane mixture $(1: 1)$.
Table I. Mass spectrometry conditions.

Mass spectrometry

\begin{tabular}{lc}
\hline Full scan & \\
Electron ionization mode & \\
Multiplier delay & 5 minutes \\
Scan range & $\mathrm{m} / \mathrm{z} 50-450$ \\
Emission current & $10 \mu \mathrm{A}$ \\
Multipler voltage & $1450 \mathrm{~V}$ \\
Maximum Ionization time & $25000 \mu \mathrm{s}$ \\
AGC prescan storage level & $\mathrm{m} / \mathrm{z} 35$ \\
Manifold temperature & $90^{\circ} \mathrm{C}$ \\
Trap temperature & $170^{\circ} \mathrm{C}$
\end{tabular}

$1 \mathrm{~g}$ of freeze dried mussel was accurately weighed and put into the Teflon-lined extraction vessel; when pentane was used as extractant solvent, the sample was wet to improve microwave heating; to prepare the wet sample, $2 \mathrm{~mL}$ of water were added and allowed to equilibrate with the sample for 5 minutes, then, the extractant solvent was added.

The extraction vessels were closed after ensuring that a new rupture membrane was used for each extraction. For this study, single extraction was performed using $50 \%$ power; the extraction time was 10 minutes, extraction temperature $\left(70\right.$ or $90{ }^{\circ} \mathrm{C}$ ) and solvent volume $(10$ or $20 \mathrm{~mL})$ depending on the experiments. After extraction, the sample carrousel was removed from microwave cavity and cooled in a water bath. The control vessel was reintroduced into the microwave unit to check that the extract was at room temperature before opening. The organic phase was filtered through anhydrous sodium sulfate.

Sample extract cleanup was performed by adding $3 \mathrm{~g}$ of alumina and shaking mechanically for 30 minutes or one hour, later the extract was filtered, and alumina was rinsed with $1 \mathrm{~mL}$ of extractant solvent, the extract was concentrated to dryness under nitrogen and then redissolved in $1 \mathrm{~mL}$ of isooctane; $10 \mu \mathrm{L}$ of PCB 155 solution was added as internal standard prior to $\mathrm{GC}$ analysis.

In some of cases 1.5 or $4 \mathrm{~mL}$ of sodium hydroxide solution $5 \%$ was added prior to microwave extraction when pentane was used as extractant solvent; afterwards, purification was performed by adding $3 \mathrm{~g}$ of alumina and shaking mechanically.

As a means of comparison, $5 \mathrm{~g}$ of sample were extracted by Soxhlet during 8 hours with $150 \mathrm{~mL}$ of pentanedichloromethane (1:1). After purification of the extract, the sample was injected in the gas chromatograph.

\section{Results and discussion \\ Validation of analytical procedure for PCB compounds}

Calibration curves have been obtained at four concentration levels using adequately diluted standards. Each 


\section{Original articles}

concentration level has been injected in duplicate, and peak heights have been fitted by linear regression. The correlation coefficient was 0.999 for all the target compounds.

Detection limits for $\mathrm{PCB}$ compounds using this procedure are: PCB31, $0.09 \mathrm{ng} / \mathrm{g}$; PCB28, $0.13 \mathrm{ng} / \mathrm{g} ; \quad$ PCB52, 0.15 ng/g; PCB101, 0.09 ng/g; PCB118, 0.19 ng/g; PCB153, 0.21 ng/g; PCB105, 0.45 ng/g; PCB138, 0.04 ng/g; PCB156, $0.08 \mathrm{ng} / \mathrm{g}$ and PCB180, $0.13 \mathrm{ng} / \mathrm{g}$.

\section{Influence of variables on microwave extraction}

In this work the following variables were studied: extraction temperature, solvent volume, solvent nature, cleanup process time and volume of sodium hydroxide solution.

Microwave extractions are usually very fast and according to recent investigations [6], the total extraction time variable affects the extraction efficiency only slightly, so this factor was fixed at 10 minutes, which was considered a sufficient time to extract all target compounds. Moreover, in the system used only the total time is a controllable factor, while the relevant factor is the time the extraction vessel takes to

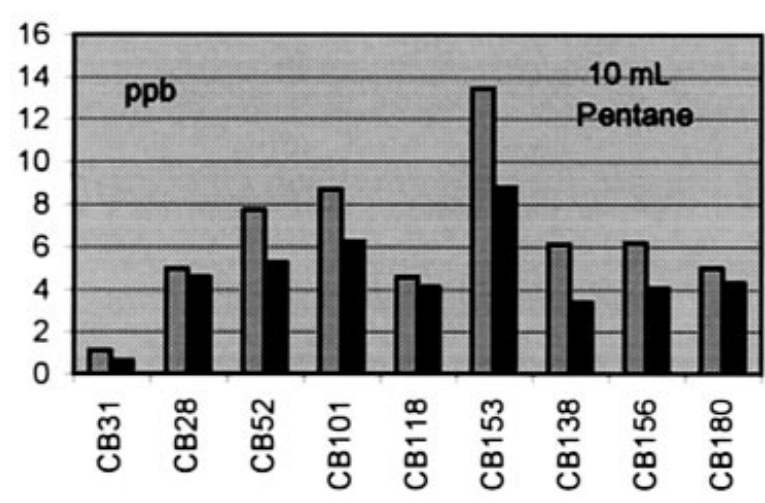

口TEMPERATURE 90C

- TEMPERATURE T0*C

Figure 1. Comparison of extraction of some PCB compounds from marine mussel microwave extracted at $70^{\circ} \mathrm{C}$ and $90^{\circ} \mathrm{C} . n=2$.
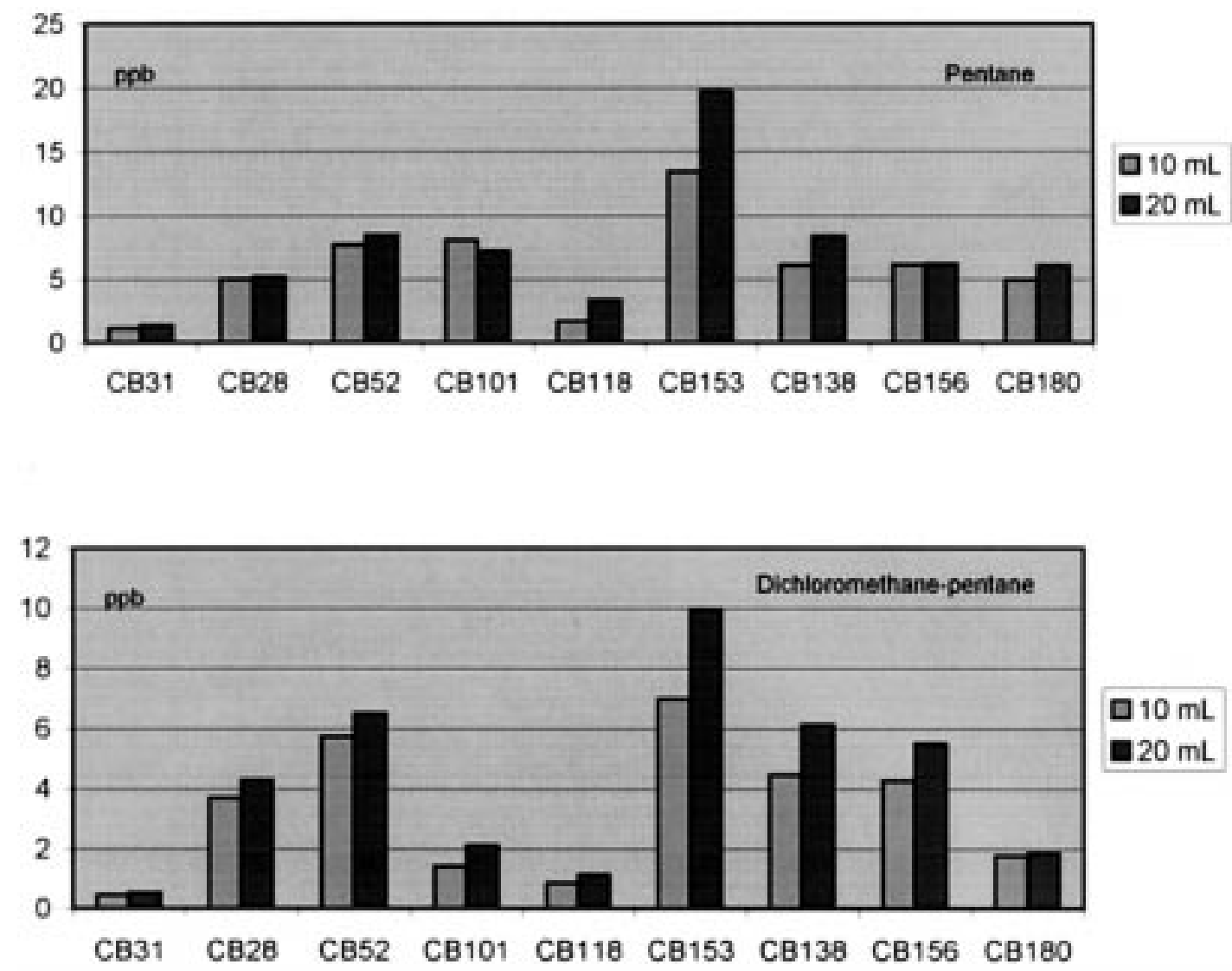

Figure 2. Comparison of extraction of some PCB compounds from marine mussel microwave extracted using 10 and $20 \mathrm{~mL}$ of pentane as extractant solvent. $n=2$. 


\section{Original articles}

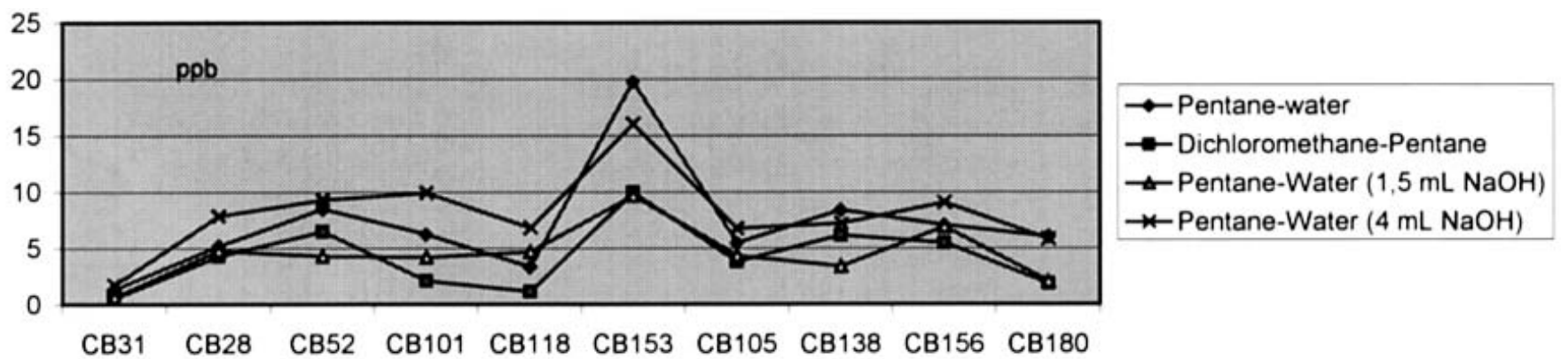

Figure 3. Comparison of extraction of some PCBs from marine mussel extracted using $20 \mathrm{~mL}$ of extractant solvent, pentane or dichloromethane-pentane mixture and in some of cases adding 1.5 or $4 \mathrm{~mL}$ of $\mathrm{NaOH}$ solution $5 \%$ to pentane solvent in the cleanup procedure. $n=2$.

attain the programmed temperature. In all experiments, the applied power was set at $50 \%$; values higher than $50 \%$ often lead to sudden increases in the pressure of the vessel with occasional breaking of the rupture membranes, thus stopping the system. In contrast, when values lower than $50 \%$ were applied, the extraction times were unnecessarily long.

With regard to extraction temperature, different experiments were carried out at $70{ }^{\circ} \mathrm{C}$ and $90{ }^{\circ} \mathrm{C}$ using a fixed volume of extractant solvent (pentane) and the same working conditions. Figure 1 shows that the maximum extraction yield has been obtained at $90^{\circ} \mathrm{C}$, then all experiments have been performed at this temperature.

In relation to solvent volume variable, when pentane was used, this variable exerts a small positive influence on recovery of the PCB compounds, so figure 2 shows the extraction efficiency is directly proportional to solvent volume: the same behavior was observed when pentane-dichloromethane (1:1) mixture was used as extractant solvent.

In general, the best recoveries are achieved when pentane was used as extractant solvent (see Fig. 3), it can be due to the dichloromethane-pentane mixture presents a higher vapour pressure, it facilitates losses of PCB compounds (semivolatile compounds) when opening the closed-vessel after microwave extraction.

With regard to cleanup process time when pentane was used, thirty minutes of shaking time were enough to obtain a good extraction, nevertheless chromatograms contain a lot of impurities that make more difficult identification and determination of target compounds. To improve the cleanup step and extraction yields, a sodium hydroxide solution $5 \%$ was added prior to sample microwave extraction, in this way it facilitates the release of the PCB fraction bounded to mussel fat and the removal of free lipids from mussel. Figure 3 shows the best recoveries are achieved when $4 \mathrm{~mL}$ of this solution were added. Two chromatograms obtained for a freeze dried marine mussel when $\mathrm{NaOH}$ solution was added and when $\mathrm{NaOH}$ solution was not added, are showed in the figure 4. As can be seen the extract is cleaner when $\mathrm{NaOH}$ solution was added.

In summary, PCBs can be optimally extracted when $1 \mathrm{~g}$ of freeze dried marine mussel plus $4 \mathrm{~mL}$ of sodium hydroxide solution $(5 \%)$ was extracted with $20 \mathrm{~mL}$ of pentane during $10 \mathrm{~min}$ at $90^{\circ} \mathrm{C}$ setting the microwave extractor at half power (see Tab. II); the cleanup process was performed by adding $3 \mathrm{~g}$ of alumina and shaking mechanically for $30 \mathrm{~min}-$ utes.

Finally, the microwave extractor procedure was validated using a certified reference material (IAEA 142, organochlorine compounds in mussel homogenate). Recoveries are included in table III. All recoveries achieved were between $77-106 \%$.

\section{Comparison with Soxhlet extraction}

The results were compared to those obtained by Soxhlet extraction. Table III shows the average recoveries and

Table II. Studied variable levels. Working conditions.

\begin{tabular}{|c|c|c|c|c|}
\hline Variable & Low level & High level & Fixed & Working conditions \\
\hline $\mathrm{NaOH}$ solution volume & $1.5 \mathrm{~mL}$ & $4 \mathrm{~mL}$ & - & $4 \mathrm{~mL}$ \\
\hline Solvent volume & $10 \mathrm{~mL}$ & $20 \mathrm{~mL}$ & - & $20 \mathrm{~mL}$ \\
\hline Extraction time & - & - & $10 \mathrm{~min}$ & $10 \mathrm{~min}$ \\
\hline Extraction temperature & $70^{\circ} \mathrm{C}$ & $90^{\circ} \mathrm{C}$ & _- & $90^{\circ} \mathrm{C}$ \\
\hline Shaking time (Clean up procedure) & $0.5 \mathrm{~h}$ & $1 \mathrm{~h}$ & - & $0.5 \mathrm{~h}$ \\
\hline
\end{tabular}




\section{Original articles}

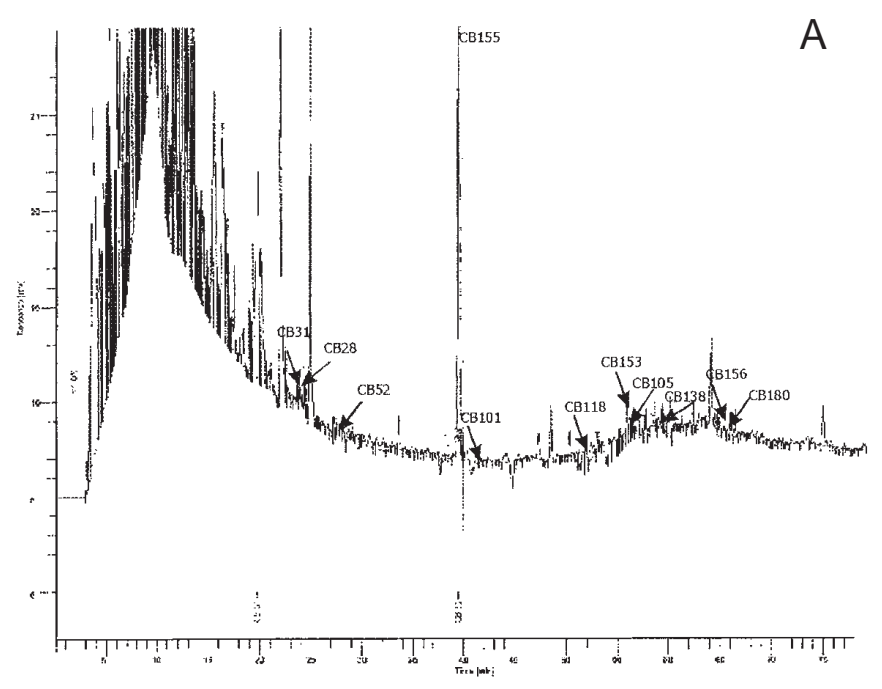

Figure 4. A) Chromatograms (GC-ECD) of target compounds obtained for a freeze dried marine mussel when $\mathrm{NaOH}$ solution was not added and $\mathrm{B}$ ) when $\mathrm{NaOH}$ solution was added in the cleanup procedure prior to microwave extraction with $20 \mathrm{~mL}$ of pentane.

Table III. Mean recoveries (\%) and precision data (relative standard deviation) for certified reference material and other performance characteristics of MASE (Microextraction Assisted Solvent Extraction) compared to Soxhlet extraction.

\begin{tabular}{|c|c|c|}
\hline & MASE & Soxhlet extraction \\
\hline Extraction time (hs) & 0.2 & 8 \\
\hline Solvent volume $(\mathrm{mL})$ & 20 & 150 \\
\hline Amount of sample $(\mathrm{g})$ & 1 & 5 \\
\hline $\begin{array}{l}\text { PCB } \\
\text { compound }\end{array}$ & $\begin{array}{l}\text { MASE } \\
(\%) \text { recovery } n=3\end{array}$ & $\begin{array}{l}\text { Soxhlet extraction } \\
(\%) \text { recovery } n=6\end{array}$ \\
\hline 31 & $90.1 \pm 1.7$ & $69 \pm 12$ \\
\hline 28 & $91.7 \pm 1.4$ & $90 \pm 13$ \\
\hline 101 & $91.1 \pm 4.2$ & $99 \pm 10$ \\
\hline 138 & $77.0 \pm 7.8$ & $91.2 \pm 3.9$ \\
\hline 153 & $102 \pm 10$ & $98.7 \pm 4.5$ \\
\hline 105 & $103.4 \pm 2.2$ & $85.7 \pm 4.0$ \\
\hline 118 & $86.9 \pm 1.8$ & $89.1 \pm 6.0$ \\
\hline 156 & $106 \pm 20$ & $90 \pm 13$ \\
\hline 180 & $99 \pm 13$ & $89 \pm 10$ \\
\hline
\end{tabular}

precision obtained of each PCB, as well as some operating features of both procedures. It can be seen that both procedures produce similar recoveries, but the MASE is advantageous from the point of view of sample handling, amounts of sample and extractant, total run time and automation.

\section{References}

1. Alvarez Piñeiro, M.E.; Simal Lozano, J.; Lage Yusty, M.A.; Carril González-Barros, S.T. Talanta 1996, 43, 487-491.
2. Ballschmiter, K. H.; Zell, M. Fresenius Z. Anal. Chem. 1980 , 302, 20-31.

3. Lopez Avila, V.; Young, R.; Benedicto, J.; Kim, R.; Ho, R.; Beckert, W.F. Anal Chem. 1995, 67(13), 2096-2102.

4. Onuska, F.I.; Terry, K.A. Chromatographia 1993, 36, 191-194.

5. Lopez Avila, V.; Young, R.; Kim, R. J. of Chromatographic Science 1995, 33, 481-484.

6. Carro, N.; Saavedra, Y.; García, I.; Llompart, M. J. Microcolumn Separations 1999, 7(11), 544-549.

7. Lao, R.C.; Shu Y.Y.; Holmes, J.; Chiu, C. Microchemical 1996, 53, 99-108.

8. Xion, G.; He, X.; Zhang, Z. Analytica Chimica Acta 2000, 4956.

9. Barnabas, I.J.; Dean, J.R.; Fowlis, I.A.; Owen, S.P. Analyst 1995, 120, 1897-1904.

10. Lopez-Avila, V.; Young, R.; Beckert, W.F. Anal. Chem. 1994, 66, 1097-1106.

11. Paré, J.R.J.; Belanger, J.; Stafford, S.S. Trends Anal. Chem. 1994, 13(4), 176-182.

12. Zlotorzynski, A. C.R.C. in Analytical Chemistry 1995, 25(1), 43-76.

13. García-Ayuso, L.E; Sanchez, M.; Fernández de Alba, A.; Luque de Castro, M.D. Anal. Chem. 1998, 2426.

14. Paré, J.R.J. et al. U.S. Patent, 1991, 5, 002, 784, Environment Canada.

15. Erickson, M.D. Analytical Chemistry of PCBs; CRC Press; Second Edition; 1997. Chapter 2.

16. Fuoco, R.; Colombini, M.P.; Samcova, E. Chromatographia 1993, 36, 65-70.

17. Lang, V. J. Chromatography 1992, 595, 1-43.

18. Alvarez Piñeiro, M.E.; Simal, Lozano, J.; Lage Yusty, M.A. Marine Pollution Bulletin 1995, 7(30), 484-487.

19. Alvarez Piñeiro, M.E.; Simal Lozano, J.; Lage Yusty, M.A. J. AOAC Int. 1994, 77, 985-988.

20. Thompson, A.; Allen, J.R.; Dodoo, D.; Hunters, J.; Hawkins, S.J.; Wolff, G.A. Marine Pollution Bulletin 1996, 32, 232-237. 